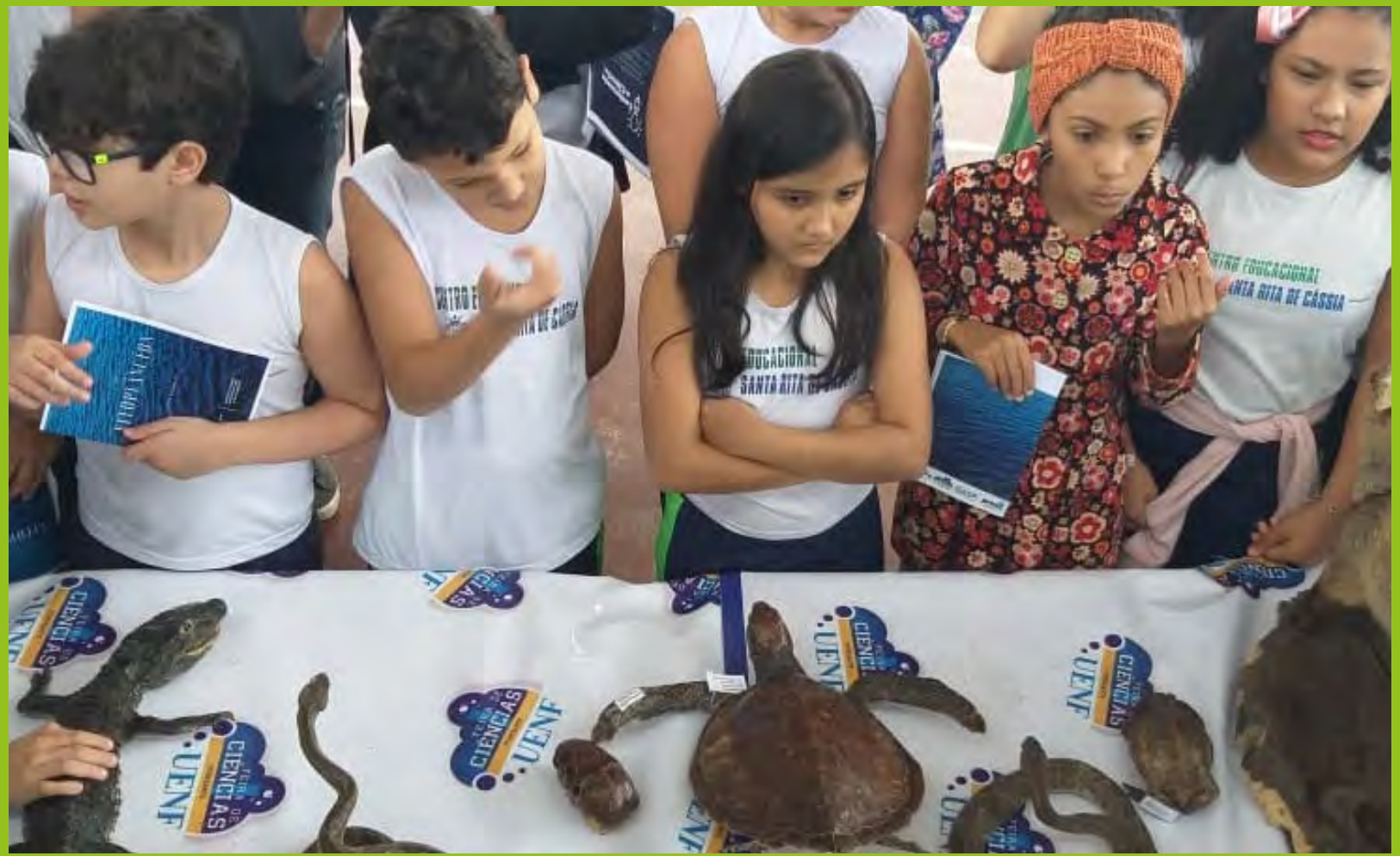

\title{
Feira de Ciências Itinerante e Exposições Sistematizadas: ferramentas didáticas inclusivas para a educação ambiental
}

Ana Bárbara Freitas Rodrigues Godinho - anaanatomiaanimal@gmail.com¹

Ketlynn Passos Alvarenga - ketlynnalvarenga@outlook.com²

Mariana Biscaro Zófoli - marianazofoli@hotmail.com³

Adriana Jardim de Almeida - drijardim@yahoo.com.br ${ }^{4}$

\section{RESUMO}

Entende-se a necessidade de ações que promovam uma educação ambiental dinâmica, multidisciplinar e baseada no processo de ensino-aprendizagem de forma direcionada a todos os cidadãos, incluindo as pessoas deficientes. Desta forma, foi realizado um trabalho interativo de divulgação científica, por meio de feiras de ciências itinerantes e exposições sistematizadas, nas quais animais taxidermizados foram utilizados para proporcionar conhecimentos a diferentes grupos da sociedade. Por meio de exposições sistematizadas em uma instituição que assiste pessoas deficientes, foi possível trabalhar os conceitos de educação ambiental. Essas atividades proporcionaram ao público-alvo um entendimento específico sobre diferenças morfológicas e sobre a importância da educação ambiental para a formação de um cidadão consciente.

PALAVRAS-CHAVE: educação não formal; meio ambiente; pessoas deficientes.

1 Doutora em Ciência Animal e professora de Anatomia dos Animais Domésticos na Universidade Estadual do Norte Fluminense Darcy Ribeiro.

2 Graduada em Engenharia Civil pela Universidade Candido Mendes e bolsista do Projeto de Extensão pela Universidade Estadual do Norte Fluminense Darcy Ribeiro.

3 Doutoranda em Ciência Animal e voluntária no Projeto de Extensão pela Universidade Estadual do Norte Fluminense Darcy Ribeiro. 4 Doutora em Ciência Animal e professora de Terapêutica e Saúde do Ecossistema pela Universidade Estadual do Norte Fluminense Darcy Ribeiro. 


\title{
Travelling Science Fair and Systematized Exhibitions: inclusive didactic tools for environmental education
}

\begin{abstract}
It is understood that there is a need for actions that promote a dynamic, multidisciplinary environmental education based on the teaching-learning process in a way that encompass all citizens, including people with disabilities. In this way, an interactive work of scientific dissemination was carried out by means of itinerant science fairs and systematized exhibitions, where taxidermized animals were used to provide knowledge for different groups in society. Through systematized exhibitions at an institution that assists people with disabilities, it was possible to work on the concepts of environmental education. These activities provided the target audience with a specific understanding of morphological differences and the importance of environmental education for the formation of a conscious citizen.
\end{abstract}

KEYWORDS: non-formal education; environment; disabled people.

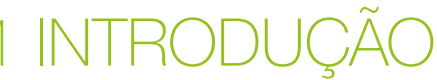

Nas últimas décadas, o planeta Terra assiste a uma crise ambiental que reflete diretamente na vida de todos os seres vivos, incluindo o ser humano. A preocupação com a sustentabilidade do planeta volta suas atenções para o desenvolvimento de políticas públicas e mudanças de atitudes pessoais e coletivas para diminuir os impactos negativos gerados pela ação do homem contra o equilíbrio dos ecossistemas e da vida (MENEZES, 2007).

A educação ambiental pode ser vista como uma forma de intervenção na problemática ambiental, mediadora de programas educativos que começaram antes e que vão além da escola formal. No Brasil, a prática da educação ambiental já é regulamentada pela Lei 9.795/1999 (BRASIL, 1999) e diz:

Art.1ํ. Entende-se por educação ambiental os processos pelo meio dos quais o indivíduo e a coletividade constroem valores sociais, conhecimentos, habilidades, atitudes e competências voltadas para a conservação do meio ambiente, bem do uso comum do povo, essencial à sadia qualidade de vida e sua sustentabilidade. Art.2‥ A Educação Ambiental é um componente essencial e permanente da educação nacional, devendo estar presente, de forma articulada, em todos os níveis e modalidades do processo educativo em caráter formal e não formal. (BRASIL, 1999, p. 1).

0 conceito de educação é muito amplo e pode ser trabalhado de três enfoques: a educação formal, a educação informal e a educação não formal. A educação formal, como já se conhece, é organizada, acontece em local específico, sistematizada, com análise de conteúdo e regulada por leis e normas da instituição de ensino (LIMA et al., 2019). Diferentemente da educação formal, a informal se adquire no processo de socialização, dentro da família, com amigos e na comunidade. É uma ação de todo o meio sociocultural sobre seus participantes (GOHN, 2006).

Educação não formal é mais difusa, menos hierárquica e menos burocrática. Desenvolve-se nos espaços não convencionais de educação, normalmente fora dos espaços escolares. Tem como finalidade desenvolver o ensino-aprendizagem, apesar de ser pouco assistida pelo ato pedagógico (ALMEIDA, 2014).

A educação ambiental requer ações de sensibilização que vão além do espaço escolar. É importante frisar que essas práticas educativas devem ser desenvolvidas de uma perspectiva crítica, que transcenda a mera "transmissão de conhecimentos" ecologicamente corretos (GUIMARÃES, 2004). Nesse sentido, não apenas os espaços de educação formal são capazes de contribuir para o processo educativo dos indivíduos. É necessário compor um conjunto articulado e permeável às possibilidades de educação ambiental, também em espaços de educação não formal, visando a uma educação voltada para a construção da cidadania, por meio de uma aprendizagem crítica e reflexiva (FREITAS; BERNARDES, 2013). 
Segundo Jacobucci (2008), o termo "espaço não formal" tem sido utilizado por pesquisadores em educação, professores de diversas áreas do conhecimento e profissionais que trabalham com divulgação científica para descrever lugares onde é possível desenvolver atividades educativas. Apesar disso, alguns estereótipos, erroneamente, ainda recaem sobre a educação ambiental não formal, caracterizando-a como uma educação na qual falta informação, investimento e capacitação (TOZONI-REIS et al., 2012).

A inserção social é indispensável para que todo ser humano seja aceito como um integrante participativo da sociedade. Pessoas deficientes, qualquer que seja a origem e características de sua deficiência, devem ter assegurados seus direitos fundamentais de exercer a sua cidadania. A eles devem ser concedidas iguais oportunidades de participação social, segundo suas capacidades de desempenho, sem discriminações (BRASIL, 2008). Segundo dados do IBGE (2010), 23,9\% da população nacional possuem algum tipo de deficiência física, mental ou sensorial. Dessa porcentagem, os deficientes visuais representam o maior grupo, correspondendo a 18,8\%.

Vygotsky (1988) afirma que, por meio da mediação social, é possível utilizar o concreto como "um ponto de apoio necessário e inevitável" para o desenvolvimento do pensamento abstrato. Para o autor, o melhor encaminhamento pedagógico é aquele que desenvolve, por meio do pensar, a abstração e a generalização. Para Soares (2004), não basta saber ler e escrever. É necessário saber fazer uso das práticas sociais da leitura e escrita, num processo de compreensão, por meio do qual o indivíduo seja capaz de produzir sentido para a linguagem e, assim, chegar às suas próprias descobertas, análises e sínteses.

Segundo Freire (2006), o processo educativo objetiva despertar nos indivíduos a consciência crítica a respeito do meio em que estão inseridas para então propor possíveis sugestões que possibilitem a realização de mudanças nesse ambiente. A propósito, a conscientização ambiental deve ser apresenta a cada cidadão, fazendo com que ele reflita sobre si, desenvolva o seu senso crítico e procure ver de que forma irá contribuir com a melhoria ou com a eliminação de situações danosas ao homem e à natureza (DOHME; DOHME, 2002).

Diante de tal contexto, este trabalho, tendo como pano de fundo o conhecimento da morfologia animal e, consequentemente, a questão ambiental, configurou-se em um tipo de educação não formal, caracterizada como Feira de Ciências Itinerante da Universidade Estadual do Norte Fluminense Darcy Ribeiro e Exposições Sistematizadas. 0 objetivo principal foi utilizar os espaços de educação não formal para divulgar entre estudantes do ensino fundamental e médio, pessoas deficientes e em diferentes grupos da sociedade, conhecimento científico voltado para preservação ambiental.

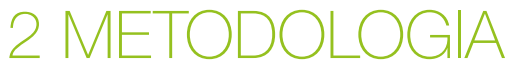

Dentro da proposta de educação não formal, foramutilizadas duas ferramentas de divulgação científica, no nível de educação ambiental: i) Feiras de Ciências Itinerantes e ii) Exposições Sistematizadas

Considerando que todos os envolvidos nesse projeto são protagonistas no processo de ensinoaprendizagem, apresentamos as Feiras de Ciências e as Exposições Sistematizadas como forma de desmistificar e popularizar a ciência para a sociedade em geral, tornando-a, realmente, significativa. Essas ações extensionistas, tendo como "pano de fundo" uma educação ambiental interdisciplinar e inclusiva, foram também formuladas para terem impacto sobre a formação acadêmico-científica dos discentes participantes. A proposta era permitir uma articulação entre ensino-pesquisa-extensão que levasse os discentes a vivenciar experiências próximas da realidade profissional e, consequentemente, transferir à sociedade conhecimentos para a construção da cidadania.

Para a execução das ações, foram realizadas as seguintes etapas: seleção dos expositores junto à Pró Reitoria de Extensão da UENF; contato com as secretarias de educação dos municípios das regiões Norte e Noroeste Fluminense para divulgação do projeto; agendamento das Feiras de Ciências e/ou Exposições Sistematizadas e, finalmente, a execução da proposta de divulgação científica.

0 conhecimento da morfologia animal trabalhado por meio dos espécimes taxidermizados foi o instrumento didático utilizado para o processo de ensino-aprendizagem nos espaços de educação não formal que tinham como público-alvo alunos de escolas municipais, estaduais e instituição de ensino especial da região Norte Fluminense; grupos de classe da sociedade civil organizada; integrantes da associação de moradores, de colônias de pescadores e de instituições ambientais.

Parte do acervo dos espécimes taxidermizados da S.A.A.D foi selecionada e trabalhada durante as Feiras de Ciências realizadas em diferentes espaços de educação não formal a partir de uma iniciativa fomentada pelo CNPQ, via aprovação de propostas de divulgação científica em editais nos anos de 2018 e 2019, e viabilizada pela Pró Reitoria de Extensão e Assuntos Comunitários da UENF, juntamente com as secretarias de educação dos municípios das regiões Norte e Noroeste Fluminense.

As Exposições Sistematizadas, por sua vez, foram executadas a partir do desenvolvimento do Projeto de extensão da UENF: "Educando para Preservar", que tinha como objetivo incorporar as espécies 
taxidermizadas ao conteúdo programático da disciplina de Ciências Naturais, trabalhada no Educandário São José Operário, instituição que atende deficientes visuais no município de Campos dos Goytacazes - RJ.

Foram utilizados diferentes espécimes animais, domésticos e silvestres, de pequeno e médio porte, em perfeito estado de conservação, que vieram a óbito ou foram eutanasiados. Após a identificação da morfologia animal externa, algumas características inerentes ao comportamento e à fisiologia desses animais, bem como seu papel no contexto ambiental regional eram abordados dentro da temática da educação ambiental e da manutenção do equilíbrio da fauna e da flora. Alicerçados pelo potencial dessa inter-relação entre os processos de educação, foi formatado um modelo de Feira de Ciências Itinerante que contou, em média, com a participação de 15 projetos de extensão, incluindo o nosso, "Educando para preservar".

\section{RESULTADOS E DISCUSSÃO}

Frente à atual crise ambiental, a educação ambiental transformadora possibilita a formação de cidadãos críticos e reflexivos, ecologicamente participativos, capazes de disseminar os princípios do desenvolvimento socioeconômico sustentável e com o objetivo de construir uma nova sociedade mais justa, politicamente atuante e consciente das relações de interdependência entre o homem e a natureza (LEAL, 2013).

Nesse mesmo sentido, é importante considerar que a escola é um local apropriado para construção do conhecimento e para reflexão das mudanças perseguidas, em prol da construção do cidadão (GATTO, 2013). No entanto, diante de nossas experiências, é possível afirmar que não apenas os espaços de educação formal são capazes de contribuir no processo educativo dos indivíduos. É necessário que haja a inter-relação entre os processos da educação formal e a educação não formal, pois nos diferentes processos existe "lugar de fala", juntamente às práticas inerentes à educação ambiental. Compreende-se que a educação não formal não substitui a educação formal. Pelo contrário, ela a complementa por meio da articulação da escola com os demais espaços da comunidade (SANTOS; PEDROSA; AIRES, 2017). Para Moraes e Silveira (2019), essa relação formal/não formal possibilita estreitar as lacunas no ensino de ciências.

Tendo como instrumento de divulgação científica as Feiras de Ciências Itinerantes idealizadas a partir das problematizações de cada público-alvo, foi possível participarmos efetivamente de 51 eventos, entre os anos de 2018 e 2019. Juntamente aos outros expositores, fomos capazes de divulgar, de maneira diversificada, ciência de qualidade e em quantidade para um público de 18.656 pessoas (Gráfico 1 e Figura 1).

Figura 1 - Quantitativo de eventos de Feiras de Ciências e de participantes entre 2018 e 2019 nas Regiões Norte e Noroeste Fluminense.

\section{FEIRAS DE CIÊNCIAS ITINERANTE}

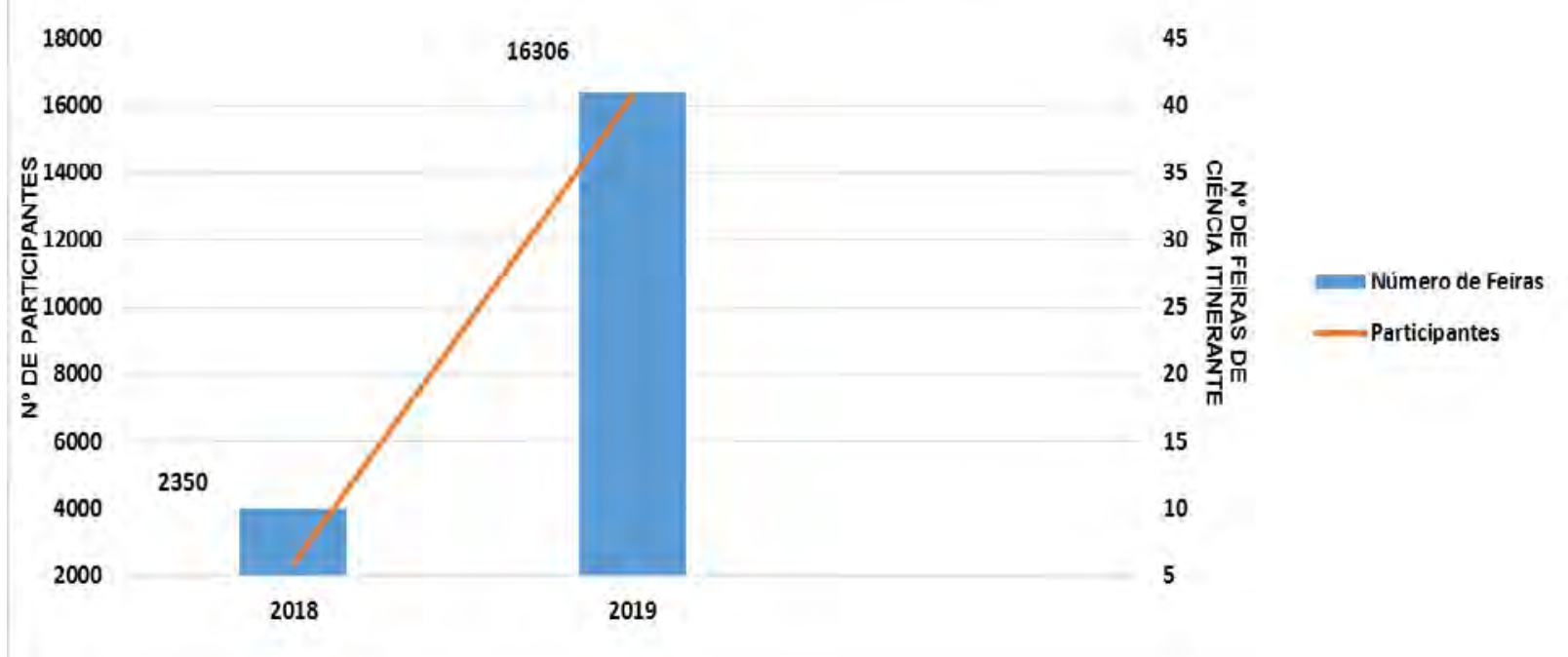


Figura 2 - Exposição de animais taxidermizados como ferramenta da educação ambiental na Feira de Ciência ltinerante, realizada no Município de Bom Jesus do ltabapoana - RJ.

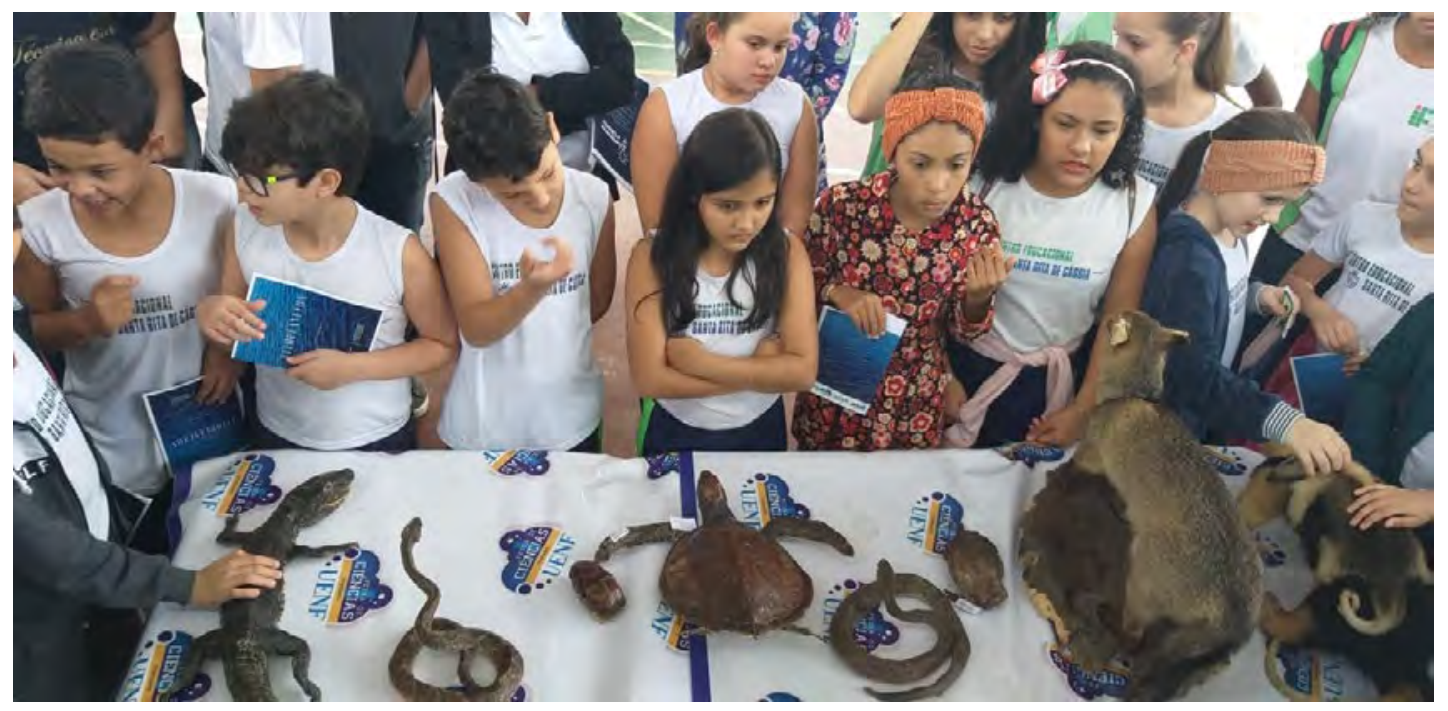

FONTE: Acervo do projeto

Após seis meses do início das atividades das Feiras de Ciências Itinerantes, passamos a atender à demanda de diversos setores da sociedade (Figura 2).

Figura 3 - Exposição de animais taxidermizados durante Feira de Ciência ltinerante da UENF, na Associação de Moradores do distrito de Espirito Santinho, Município de Campos dos Goytacazes-RJ (A), e na Feira de Ciência de São João da Barra - RJ (B).

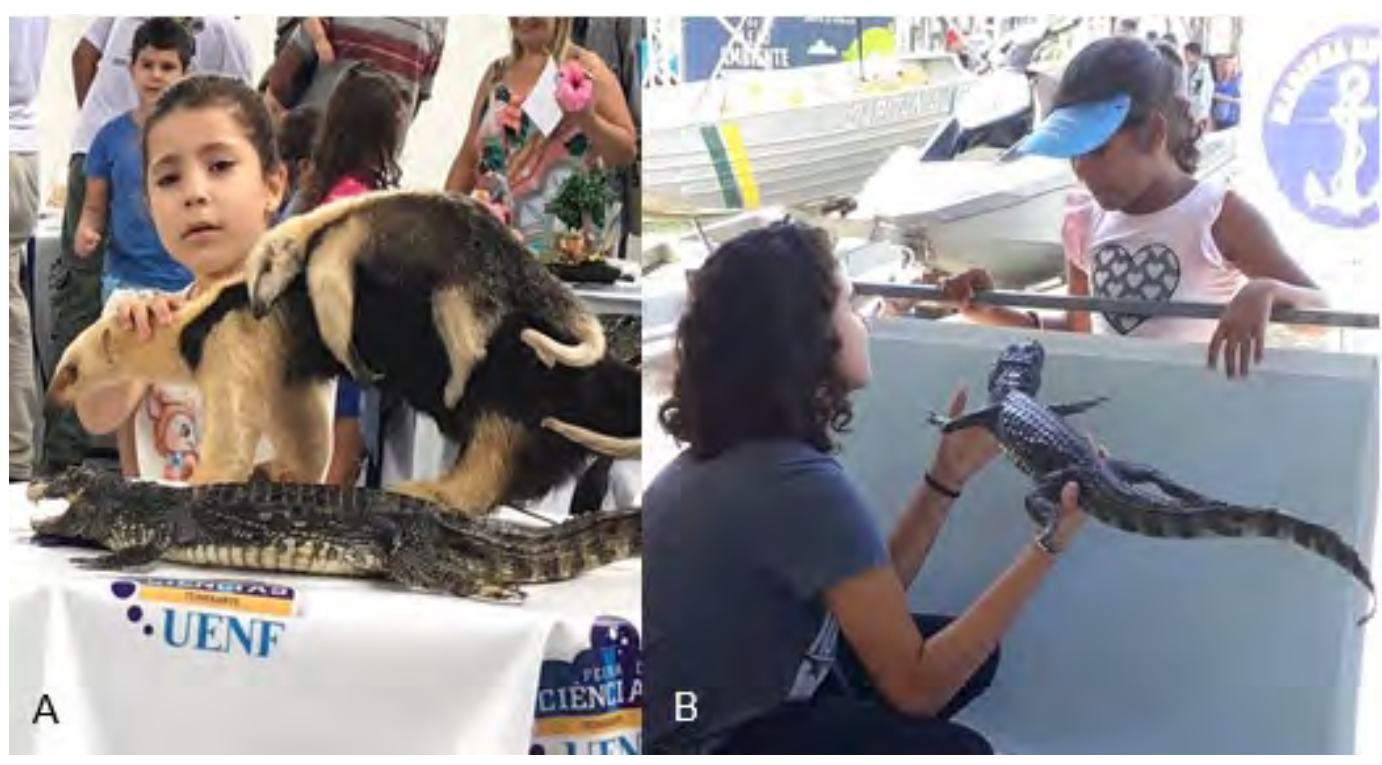

FONTE: Acervo do projeto

Nesse momento, passamos a entender que, no processo de educação não formal, os conhecimentos estavam sendo compartilhados por meio das relações socioculturais entre os indivíduos. De maneira espontânea, o processo de ensino-aprendizagem estava contribuindo para a formação de cidadãos críticos e reflexivos (GOHN, 2006).

A possibilidade de abordar as questões ambientais nas instituições voltadas para a educação especial, principalmente as que assistem deficientes visuais, impulsionou-nos a implementar uma metodologia didática alternativa para o ensino da disciplina de Ciências Naturais. Foram taxidermizados mais de 20 espécimes animais, entre eles: Pinguim-de-Magalhães, Gato Doméstico, Coelho, Cágado, Tartaruga Verde, 
Teiú, Sagui-de-tufo-preto, Cão, Atobá-pardo, Tamanduá-Mirim, Galinha, Serpentes, Frango-d’água, GaviãoCarijó, Gavião-Carcará, Coruja-das-Torres, Quati e Guaxinim. Todo esse acervo foi trabalhado com o intuito de incorporar, no processo de ensino-aprendizagem de deficientes visuais, uma ferramenta didática alternativa e conhecimento científico, embasados no processo de educação ambiental (Figura 3).

Figura 4 - Espécimes taxidermizados de uso para atividadles de educação ambiental da Seção de Anatomia Animal/LMPA/UENF: Crotalus durissus: Cascável (A), Tamandua tetradactyla: Tamaduámirim (B) e Boa constrictor: Jibóila (C).

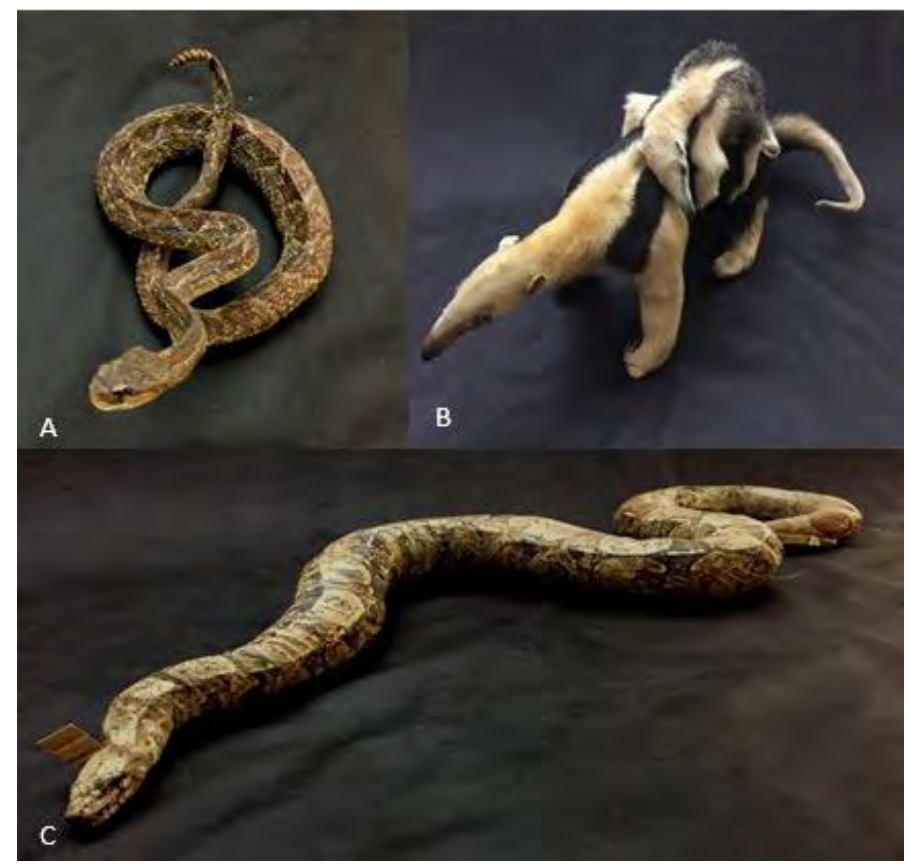

FONTE: Acervo do projeto

A Educação Ambiental pode, de fato, contribuir para a formação de uma sociedade inclusiva e sustentável. É importante deixar claro que as deficiências não são barreiras para o contato e a interação com o ambiente natural, bem como o acesso a bens e serviços ambientais (MACIEL et al, 2010).

0 uso de materiais táteis, tridimensionais e alternativos auxilia no processo de ensino-aprendizagem dos alunos deficientes visuais, diminuindo as barreiras que impedem o acesso às informações, principalmente àquelas que requerem o uso de imagens (BARRETO et al., 2014).

Considerando-se as dificuldades de acesso à aprendizagem por parte de alunos deficientes, Santos (2007) lembra que, no caso da cegueira, há uma limitação importante no processo de ensino, exigindo que as práticas educativas sejam pensadas de forma a contemplar suas peculiaridades, por meio das vias alternativas. Essas limitações podem ser frequentemente contornadas pelo uso de protótipos, pois eles podem possibilitar o acesso a uma forma de percepção da imagem. Nesse sentido, e após avalições de outras metodologias já aplicadas para o aprendizado dos deficientes, o uso da técnica de taxidermia de espécimes animais proporcionou mais aproximação do público-alvo com a realidade, fazendo com que as diferenças inerentes às características morfológicas dos animais - escamas, pelos e penas - fossem sentidas e entendidas de maneira fidedigna. A utilização de animais taxidermizados, além de despertar a consciência ambiental nos alunos, também foi capaz de desenvolver o senso crítico individual. Durante as apresentações do material didático, os espécimes não eram apenas entregues aos alunos para um simples manuseio. Existia toda uma discussão, segundo uma perspectiva interativa e dialógica (AMARAL; MORTIMER, 2006).

Dessa forma, foi possível estimular uma aprendizagem conceitual sobre vários temas, em que os alunos expuseram suas ideias, fizeram perguntas e discutiram seus pontos de vista. Foi possível constatar o grande interesse do público-alvo em perceber, principalmente por meio do tato, as características morfológicas das estruturas apresentadas (Figura 4). 
Figura 5 - Apresentação dos espécimes taxidermizados aos deficientes visuais do Educandário São José Operário. Abordagem científica sobre diferentes espécies de animais domésticos e silvestres: Tartaruga verde (A) e Galinha (B).

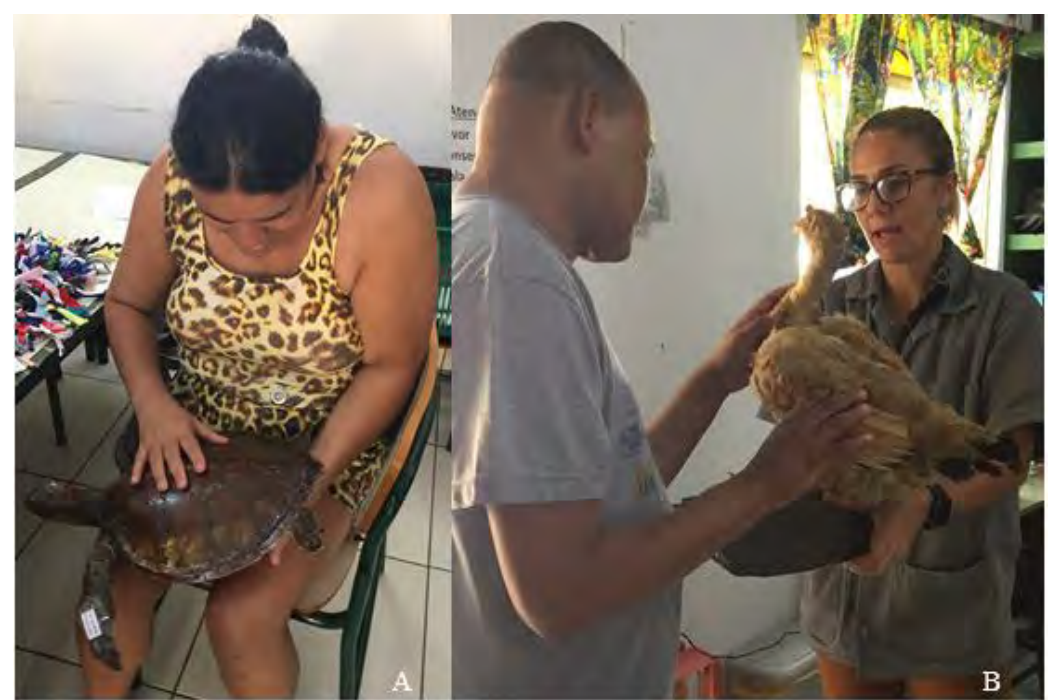

FONTE: Acervo do projeto

Segundo os professores do Educandário São José Operário, instituição parceira no desenvolvimento deste trabalho, a aplicação dessa nova metodologia teve reflexo direto no processo de ensino-aprendizagem dos alunos. Além de sedimentar o conteúdo programático da disciplina de Ciências Naturais, os alunos passaram a explorar mais a percepção tátil, a memória, a concentração e, até mesmo, a coordenação motora. Muitos deles descreveram que raramente tinham contato com animais. Principalmente por esses motivos, foram observadas demonstrações claras de surpresa e fascínio ao descobrirem os tamanhos, formatos e texturas das estruturas apresentadas.

Nesse contexto, pudemos esclarecer dúvidas que surgiram a respeito da fisiologia dos animais domésticos e silvestres, como seus hábitos alimentares, reprodutivos e habitats. Houve questionamentos sobre os principais cuidados que os tutores devem ter com seus animais domésticos e também com os membros da família, de modo a prevenir a transmissão de zoonoses. Ficou evidente o surgimento de uma consciência coletiva ao descobrirem que a colaboração de todos é fundamental no processo da proteção do meio ambiente e que, sem as medidas individuais apresentadas, aqueles animais, que estavam tão próximos deles, poderiam estar em risco.

Segundo Aranha (2004), a escola inclusiva é aquela que garante qualidade de ensino a cada um de seus educandos, reconhecendo e respeitando a diversidade e respondendo a cada um de acordo com suas potencialidades e necessidades.

Novas propostas educacionais devem fazer uso dos princípios e valores utilizados na educação ambiental, ressaltando-se o respeito e a tolerância pelo outro e pelo meio onde convivemos. Gohm (2011) afirma que sua concepção de educação não formal se articula no campo da educação cidadã, sendo esse tipo de educação um processo sociopolítico, cultural e pedagógico de formação para a cidadania, entendendo o político como a formação do indivíduo para interagir com o outro em sociedade. É preciso reconhecer a educação para além da prática formal, para além da escola (MEIRELES; DURAN, 2011). Esse é um tipo de enfrentamento, no cenário educacional, que deve ser imediato. Precisamos trabalhar novas formas e novos espaços educacionais. Para tal, o campo da educação não formal vem se apresentando como um importante campo de interesse e pesquisa.

\section{CONCLUSÕES}

A inclusão do deficiente visual como indivíduo produtivo, criativo e ativo na sociedade deve ser urgentemente implementada, para que ele desenvolva a consciência ambiental e a aplique em seu cotidiano. Fica evidente que a educação ambiental tem um importante alcance político e que sua metodologia de ação é alicerçada na análise da realidade vivida por cada indivíduo dentro da sociedade, suplantando, dessa forma, um simples processo de transmissão de conhecimentos "ecologicamente corretos". Entendemos que a 
visão transformadora e emancipatória trabalhada na educação ambiental e na educação não-formal são ações complementares e pertinentes a um contexto macro, que é a educação propriamente dita.

É de fundamental importância que todos os processos educativos despertem nos indivíduos a consciência crítica a respeito do meio em que estão inseridos. Com base nessa cultura de responsabilidade social é que as ações extensionistas devem ser idealizadas, visando à intervenção direta na realidade da sociedade local ou regional. Essas ações, mais do que nunca, devem atuar numa perspectiva dialógica, acessível e democrática. Acreditamos que as atividades extensionistas, desenvolvidas neste projeto, foram capazes de preparar os discentes e o público-alvo para o exercício da cidadania.

\section{Agradecimentos}

Agradecemos ao Educandário São José Operário pela parceria pedagógica. Ao CNPQ e à PROEX/UENF por viabilizarem a implementação de um novo projeto fundamentado na educação não formal, na educação inclusiva e na educação ambiental.

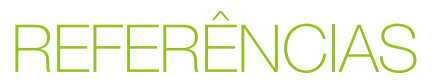

ALMEIDA, Maria Salete Bortholazzi. Educação não formal, informal e formal do conhecimento científico nos diferentes espaços de ensino e aprendizagem. Cadernos PDE, Paraná, v. 2, p. 18, 2014. Disponível em: <http:// www.diaadiaeducacao.pr.gov.br/portals/cadernospde/pdebusca/producoes pde/2014/2014 uel bio pdp maria salete bortholazzi almeida.pdf $>$. Acesso em: 20 set. 2020.

AMARAL, Edenia Maria Ribeiro do; MORTIMER, Eduardo Fleury. Uma metodologia para análise da dinâmica entre zonas de um perfil conceitual no discurso da sala de aula. In: SANTOS, Flávia Maria Teixeira; GRECA, lleana Maria (Org.). A pesquisa em ensino de ciências no Brasil e suas metodologias. Unijuí: Editora Unijuí, 2006.

ARANHA, Maria Salete Fábio. Educação inclusiva: transformação social ou retórica?. In: OMOTE, Sadão. Inclusão: intenção e realidade. São Paulo: Fundepe Publicações, 2004.

BARRETO, Inakã Silva; RESENDE FILHO, João Batista Moura de ; NASCIMENTO, Yasmine Isis Fernandes do. Ensino de Química e Inclusão: Confecção de Modelos Atômicos que facilitem a aprendizagem de alunos Deficientes Visuais. In: ANAIS DO 70 SIMPÓSIO BRASILEIRO DE ENSINO DE QUÍMICA, 7., 2009, Salvador. Anais [...]. Salvador: Associação Brasileira de Química, 2009.

BRASIL. Lei n 9.795, de 27 de Abril de 1999. Dispõe sobre a educação ambiental, institui a Política Nacional de Educação Ambiental e dá outras providências. Disponível em: < http://www.planalto.gov.br/ccivil_03/leis//9795. htm>. Acesso em: 20 set. 2020.

BRASIL. Política Nacional de Educação Especial na perspectiva da Educação Inclusiva. Inclusão: Revista de Educação Especial, Brasília, v. 4, n. 1, p. 7-17, 2008. Disponível em: < http://portal.mec.gov.br/arquivos/pdf/ politicaeducespecial.pdf>. Acessado em: 20 set. 2020.

DOHME, Vania D'Angelo; DOHME, Walter. Ensinando a criança a amar a natureza. São Paulo: Editora Informal, 2002.

FREIRE, Paulo. Educação como prática de liberdade. Rio de Janeiro: Paz e Terra, 2006.

FREITAS, Bruno de; BERNARDES, Maria Beatriz Junqueira. Educação ambiental: ações educativas em espaços não formais. In: XI CONGRESSO DE EUCAÇÃO - EDUCADORES (EDUCERE), 2013, Curitiba, Anais [...]. Disponível em: <https://educere.bruc.com.br/CD2013/pdf/7194 4592.pdf>. Acesso em: 20 set. 2020.

GATTO, Eliane. Educação ambiental e educação inclusiva: um estudo com os profissionais na escola de educação básica Jorge Lacerda - Flor do Sertão - SC. 2013. 162f. Dissertação (Mestrado) - Programa de PósGraduação Stricto Sensu em Educação, Universidade do Vale do Itajaí, Itajaí, 2013.

GOHN, Maria da Glória. Educação não-formal, participação da sociedade civil e estruturas colegiadas nas escolas. Ensaio: avaliação e políticas públicas em educação, Rio de Janeiro, v. 14, n. 50, p. 27-38, 2006. DOI: https://doi.org/10.1590/S0104-40362006000100003. Acesso em: 20 set. 2020. 
GOHN, Maria da Glória. Educação não-formal na pedagogia social. In: I CONGRESSO INTERNACIONAL DE PEDAGOGIA SOCIAL, 1., 2006, São Paulo. Proceedings online... Faculdade de Educação: Universidade de São Paulo. Disponível em: < http://www.proceedings.scielo.br/scielo. php?pid=MSC0000000092006000100034\&script=sci_arttext>. Acesso em: 20 set. 2020.

GOHM, Maria da Glória. Educação não-formal e cultura política. São Paulo: Cortez, 2011.

GUIMARÃES, Mauro. Educação ambiental crítica. In: LAYRARGUES, Phillippe Pomier (Coord.). Identidades da educação ambiental brasileira. Brasília: Ministério do Meio Ambiente, 2004.

IBGE. Censo demográfico. Brasil: IBGE, 2010. Disponível em: <https://biblioteca.ibge.gov.br/visualizacao/ periodicos/94/cd_2010_religiao_deficiencia.pdf>. Acesso em: 20 set. 2020.

JACOBUCCI, Daniela Franco Carvalho. Contribuições dos espaços não formais de educação para a formação da cultura científica. Revista Em Extensão, Uberlândia, v. 7, n. 1, p. 55-66, 2008.

LEAL, Maria da Conceição dos Reis. Inovação curricular? Educadores para uma Sociedade Sustentável. São Paulo: Paco Editorial, 2013.

LIMA, Edwiges Inácia de; NAGAO, Fernanda Quinei Alves; SELMO, Jaqueline Tumitan; LANDIM, Sorrana Penha Paz; LIMA, Vanda Moreira Machado. 0 papel da educação formal, não formal e informal na formação política de mulheres educadoras. Revista Pegada, v. 20, n. 1, p. 270-286, 2019. D0I: https://doi.org/10.33026/peg. v20i1.6305.

MACIEL, Jaqueline Lessa; WACHHOLZ, Chalissa Beatriz; ALMINHANA, Clarissa Oliveira; BITAR, Paloma Gusmão; MUHLE, Rita Paradela. Metodologias de uma educação ambiental inclusiva. Porto Alegre: EGP, 2010.

MEIRELES, Tatiane de Fátima Wanzeler; DURAN, Marília Claret Geres. 0 desafio do pedagogo nos espaços de educação não formal. Revista Múltiplas Leituras, São Paulo, v. 4, n. 2, p. 131-133, 2011. D0I: http://dx.doi. org/10.15603/1982-8993/ml.v4n2p131-133.

MENEZES, Débora. Em defesa do planeta. São Paulo: Nova Escola, 2007. Disponível em: $<$ https://novaescola. org.br/conteudo/1170/em-defesa-do-planeta\#_=>. Acesso em: 23 set. 2020.

MORAES, Leandro Donizete; SILVEIRA, Ismar Frango. 0 Estado da Arte da pesquisa em educação não formal em Astronomia no Brasil: uma análise de Teses e Dissertações. Revista de Ensino de Ciências e Matemática, São Paulo, v. 10, n. 3, p. 188-203, 2019. Disponível em: <http://revistapos.cruzeirodosul.edu.br/index.php/rencima/ article/view/2261/1137>. Acesso em: 23 set. 2020.

RAZUCK, Renata Cardoso de Sá Ribeiro; GUIMARÃES, Loraine Borges. 0 desafio de ensinar modelos atômicos a alunos cegos e o processo de formação de professores. Revista Educação Especial, Santa Maria, v. 27, n. 48, p. 141-154, 2014. DOl: http://dx.doi.org/10.5902/1984686X4384.

SANTOS, Lucelena Fernanda Ferreira dos; PEDROSA, Letícia Leonardi; AIRES, Joanes Aparecida. Contribuições da Educação Não Formal para Educação Formal: Um Estudo de Visitas de Alunos da Educação Básica ao Departamento de Química da UFPR. ACTIO, Curitiba, v. 2, n. 1, p. 456-473, 2017. DOI: 10.3895/actio.v2n1.6804

SANTOS, Miralva Jesus dos. A escolarização do aluno com deficiência visual e sua experiência educacional. 2007. 115f. Dissertação (Mestrado) - Pós-Graduação em Educação, Universidade Federal da Bahia, Salvador, 2007.

SOARES, Magda. Letramento e alfabetização: as muitas facetas. Revista Brasileira de Educação, n. 25, p. 5-17, 2004. DOI: https://doi.org/10.1590/S1413-24782004000100002.

TOZONI-REIS, Marília Freitas de Campos et al. A educação ambiental na escola básica: diretrizes para a divulgação dos conhecimentos científicos. Pesquisa em Educação Ambiental, v. 7, n. 1, p. 29-48, 2012. DOI: 10.18675/2177-580X.vol7.n1.p29-48.

VYGOTSKY, Lev. Pensamento e linguagem. São Paulo: Martins Fontes, 1988. 